'TITISARI JUWITANINGTYAS, 2ERNA ASTUTI, ${ }^{3}$ ALI TARMUJ

${ }^{1}$ Program Studi Teknologi Pangan, Fakultas Teknologi Industri

${ }^{2}$ Program Studi Teknik Kimia, Fakultas

Teknologi Industri

${ }^{3}$ Program Studi Teknik Informatika, Fakultas

Teknologi Industri

Universitas Ahmad Dahlan

Jalan Ringroad Selatan, Kragilan, Tamanan,

Kecamatan Banguntapan, Bantul, Daerah

Istimewa Yogyakarta 55191

Email: titisari.juwitaningtyas@tp.uad.ac.id

\section{Penguatan Teknologi Olah Buah Salak dalam Upaya Peningkatan Kualitas Produk}

\author{
Salak Fruit Processing Technology Empowerment in Ef- \\ forts to Improve Product Quality
}

https://doi.org/10.18196/bdr.8284

\begin{abstract}
Salak pondoh is a typical fruit of Sleman Regency which has been known domestically and abroad. Salak pondoh fruit has been generally marketed in fresh and processed form. The Agawe Santosa Community Association (MAS) located in Turi District, Sleman is one of the Micro, Small and Medium Enterprises (MSMEs) that produces various processed salak fruit. The availability of the fresh fruit as raw material for processing salak fruit has fluctuated due to the season, so the volume of processed salak fruit products also becomes unstable. This condition gets even worse because of the fruit processing technology which is still conventional. Efforts to maintain volume stability of salak fruit processed products need to be done so that fluctuations in producer income can be reduced. Community empowerment program or UMKM through strengthening the technology of salak fruit is a solution to maintain this stability. The empowerment of salak fruit processing technology is through the application of Vacuum Frying Technology (low pressure vacuum frying). This technology is able to guarantee that salak fruit processed products can be stored for a relatively long time. The application of Vacuum Frying technology is carried out in several stages, which are introduction, education (training and technology transfer practices), mentoring, and post-practice monitoring of technology application so that sustainability is guaranteed. Empowerment of UMKM Paguyuban MAS is said to be successful with indicators of increasing knowledge and skills in using Vacuum Frying (especially chips products) by $58.4 \%$, packaging processed salak fruit products (chips) and production management by $60 \%$, as well as guaranteeing business sustainability.

Keywords: skills, chips, salak fruit processing, packaging, vacuum frying
\end{abstract}

\title{
PENDAHULUAN
}

Buah salak merupakan komoditas buah tropis yang mempunyai zat gizi tinggi. Di provinsi Daerah Istimewa Yogyakarta, buah ini banyak dihasilkan di Kecamatan Turi, Kabupaten Sleman. Terdapat berbagai varian buah salak seperti salak madu, salak pondoh, salak manggala, dan salak lumut. Buah salak mempunyai masa simpan yang pendek. Masyarakat di daerah ini biasa menjual langsung buah salak segar atau mengolahnya menjadi produk olahan sepeerti dodol salak, manisan salak, selai salak, dan wingko salak. Salah satu kelompok masyarakat ekonomi produktif yang melakukan usaha berbasis 
pengolahan buah salak ini adalah Paguyuban Manunggal Agawe Santosa (MAS). Paguyuban MAS berlokasi di Desa Wonokerto, Kecamatan Turi, Kabupaten Sleman, DIY. Desa Wonokerto merupakan salah satu desa yang berada di lereng Gunung Merapi, tepatnya di Kecamatan Turi, Kabupaten Sleman, Daerah Istimewa Yogyakarta. Desa Wonokerto secara geografis terletak di ketinggian 400-900 di atas permukaan laut. Pada level ketinggian tersebut mengakibatkan Desa Wonokerto bersuhu sejuk sampai dengan dingin serta sangat cocok untuk usaha pertanian. Lokasi ini berjarak kurang lebih 30 kilometer dari Kampus 4 Universitas Ahmad Dahlan (Gambar 1). Secara umum Desa Wonokerto mempunyai potensi pertanian terbesar berupa perkebunan salak pondoh. Salak pondoh (Sallaca edulis Reinw cv Pondoh) merupakan hasil perkebunan terbesar dari Kecamatan Turi, Kab. Sleman. Produksi salak pondoh dari Kecamatan Turi menempati peringkat nomor 2 terbesar di Provinsi Daerah Istimewa Yogyakarta. Salak pondoh asli Kecamatan Turi memiliki cita rasa yang berbeda, yaitu manis dan daging buah yang tebal. Potensi ini mengakibatkan Kecamatan Turi menjadi sebuah predikat tersendiri di Indonesia yaitu sebagai Sentra Salak Pondoh (Pemetaan Swadaya TIP Desa Wonokerto, 2011).

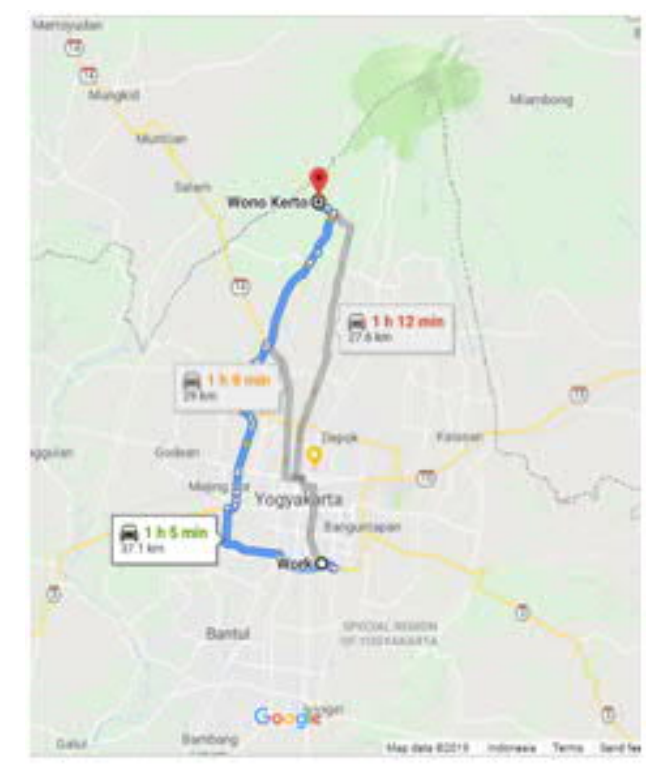

Gambar 1. Peta Lokasi Kegiatan Pengabdian Masyarakat Sumber: www.google.maps.com

Paguyuban MAS selama ini sudah melakukan pengolahan buah salak menjadi beragam produk seperti dodol salak, manisan salak, sari buah salak, dan wingko salak. Kendala yang dihadapi oleh kelompok ini adalah kontinyuitas produksi serta naik turunnya harga buah salak dikarenakan perubahan musim akhir-akhir ini. Pemasaran yang masih terbatas pada system made by order yang mengakibatkan produktivitas kelompok ini belum opti- 


\section{5}

mal. Produk sari salak dianggap menjadi produk unggulan dan mempunyai kuantitas produksi paling konsisten di antara varian olahan salak yang lain. Pada musim liburan atau hari raya, paguyuban ini mampu memproduksi rata-rata 3000 cup.

Paguyuban MAS belum pernah mengolah buah salak menjadi keripik salak terutama menggunakan teknologi vacuum frying. Penggorengan buah dapat dilakukan melalui metode penggorengan biasa dengan pencelupan bahan pada minyak goreng dalam kondisi tekanan atmosfer (deep frying) dan penggorengan pada kondisi hampa udara dan tekanan rendah (vacuum frying). Cara penggorengan tergantung pada jenis buah dan kadar airnya. Untuk buah-buahan yang mempunyai kadar air yang tinggi seperti salak, nanas, dan papaya, penggorengan dilakukan dengan metode vacuum frying (Tumbel, 2017). Penelitian mengenai penggorengan hampa atau vacuum frying untuk rekayasa proses pengolahan pangan telah banyak dilakukan khususnya untuk diterapkan pada berbagai komoditas buah dan sayur seperti kentang (Garayo et al., 2001; Troncoso \& Pedreschi, 2009), apel (Mariscal et al., 2007), wortel (Dueik et al., 2010), dan pisang (Wijayanti, 2011).

Buah salak mempunyai kadar air yang tinggi sehingga mengakibatkan sifat dari buah tersebut mudah busuk (perishable). Maka dari itu dibutuhkan teknologi pengolahan yang dapat memperpanjang umur simpan dari buah tersebut. Teknologi penggorengan dengan metode vacuum frying dapat diaplikasikan pada buah salak untuk menghasilkan keripik salak. Buah salak bersifat musiman. Pada musim panen, buah dapat berjumlah sangat melimpah. Hal tersebut mengakibatkan harga jual yang anjlok bahkan tidak mempunyai nilai ekonomis sehingga terkadang membuat kerugian bagi petani salak. Selain memperpanjang umur simpan, adanya aplikasi teknologi vacuum frying ini diharapkan mampu meningkatkan nilai ekonomis buah salak sehingga menambah pendapatan masyarakat khususnya kelompok Paguyuban MAS. Melihat situasi saat ini, maka kegiatan pengabdian kemitraan masyarakat ini (PKM) bertujuan untuk melatih masyarakat kelompok Paguyuban MAS untuk menggunakan alat vacuum frying untuk mengolah buah salak menjadi keripik salak.

\section{METODE PELAKSANAAN}

Kegiatan pengabdian masyarakat ini terselenggara atas kemitraan tim dengan Paguyuban MAS. Waktu pelaksanaan yaitu pada bulan Juli-September tahun 2019. Tahapan pelaksanaan kegiatan ini adalah sebagai berikut:

1. Tahap I: Survey lokasi

Survey lokasi yang dilakukan meliputi perkenalan tim, update kondisi terkini, serta koordinasi mengenai waktu dan tempat pelaksanaan. 
2. Tahap II: Penjelasan mengenai teknologi vacuum frying

Penjelasan mengenai teknologi vacuum frying menggunakan metode presentasi.

Presentasi dilakukan secara aktif yaitu melalui penjelasan dan diskusi dengan peserta.

3. Tahap III: Praktik penggunaan alat vacuum frying

Teknologi vacuum frying merupakan pengetahuan baru bagi kelompok Paguyuban MAS.

Pengenalan mengenai alat ini dilakukan dengan praktik langsung pembuatan keripik salak. Mesin vacuum frying ditunjukkan pada Gambar 2.

4. Tahap IV: Evaluasi Program

Kegiatan ini dilakukan untuk mengetahui dampak program kepada penerima program (Kelompok Paguyuban MAS).

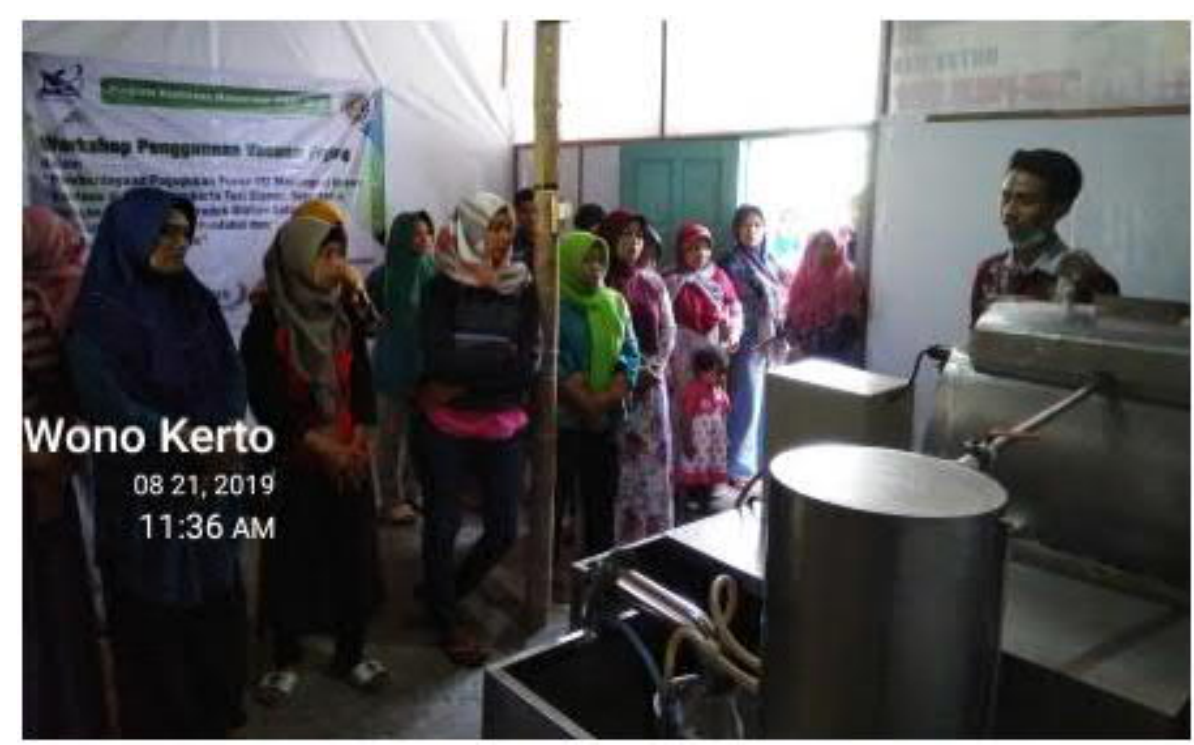

Gambar 2. Pelatihan Praktik Penggunaan Alat Vacuum frying

Pada pelaksanaan kegiatan, masyarakat diberikan penjelasan mengenai tahapan pengolahan buah salak segar menjadi keripik salak. Langkah yang dilakukan adalah:

1. Memasukkan minyak goreng sebanyak 35-38 liter ke dalam bak vacuum frying.

2. Mengatur suhu pemanasan pada $70-75^{\circ} \mathrm{C}$. Pemanasan membutuhkan waktu selama kurang lebih 1 jam

3. Mengupas buah salak segar, membersihkan kulit arinya, membelah buah secara vertikal dan menghilangkan bijinya.

4. Mencuci buah yang sudah dibelah hingga kulit arinya sudah tidak lagi menempel pada daging buah.

5. Memasukkan buah salak saat tekanan dalam vacuum frying $-60 \mathrm{~atm}$. 
6. Menyalakan pompa vakum

7. Menggoreng buah salak selama 30 menit (per 1 kilogram).

\section{HASIL DAN PEMBAHASAN}

Kegiatan pengabdian kepada masyarakat yang dilakukan merupakan sebuah upaya penguatan teknologi pada proses produksi pengolahan buah salak menjadi keripik salak. Beberapa hal yang dilakukan pada program ini yaitu melatih masyarakat untuk menggunakan alat vacuum frying sebagai alat pemrosesan buah salak menjadi keripik salak, melatih masyarakat dalam pengemasan produk, serta melatih masyarakat dalam mengaplikasikan marketplace atau digital marketing sebagai upaya memaksimalkan kegiatan pemasaran produk.

Buah salak mempunyai sifat yang tidak tahan lama dalam penyimpanan dan membutuhkan ruangan yang cukup besar (Nugraha, 2012), maka dari itu perlu dilakukan pengolahan agar memperpanjang umur simpan dan dapat dikonsumsi dalam jangka waktu yang lama (Bremeer, 2018). Keripik buah hasil penggorengan sistem hampa memiliki rasa, aroma, seperti buah aslinya, tekstur renyah serta nilai gizinya yang relatif dapat dipertahankan (Tumbel dan Manurung, 2017). Penelitian sebelumnya terkait dengan keripik buah dengan teknologi penggorengan hampa yang pernah dilakukan antara lain Wijayanti et al. (2011) pada keripik pisang, Iswari (2013) pada keripik ubi jalar, dan Tumbel dan Manurung (2017) pada keripik nanas.Pelatihan pengolahan buah salak menjadi keripik salak diawali dengan pengenalan prinsip kerja dan metode penggunaan teknologi vacuum frying kepada masyarakat. Buah salak diperoleh dengan memanfaatkan hasil kebun salak yang dimiliki warga. Buah salak dipilih yang matang, segar, dan tidak memar. Ujung buah dipotong atau dihilangkan karena bagian tersebut mempunyai tingkat ketebalan yang tinggi, yang mengakibatkan ketebalan buah tidak merata dan gosong saat digoreng. Vacuum frying diatur pada tekanan - 60 atm dan suhu $70^{\circ}-80^{\circ} \mathrm{C}$ dan proses dilakukan hingga embun pada alat vacuum frying hilang. Penirisan dilakukan dengan memasukkan keripik salak pada mesin spinner agar minyak yang menempel pada produk dapat turun dan hilang dari produk. Selain pelatihan penerapan teknologi vacuum frying, masyarakat juga dibekali pengetahuan mengenai pengemasan produk yang baik serta pemasaran digital menggunakan media marketplace.

Berdasarkan program yang kami lakukan, hasil yang didapatkan melalui program pengabdian kemitraan masyarakat ini antara lain:

1. Pengetahuan dan keahlian masyarakat menjadi meningkat. Teknologi pengolahan menggunakan vacuum frying merupakan penerapan IPTEK yang baru bagi masyarakat. 
2. Keberhasilan mengolah produk keripik salak menambah diversifikasi produk bagi mitra.

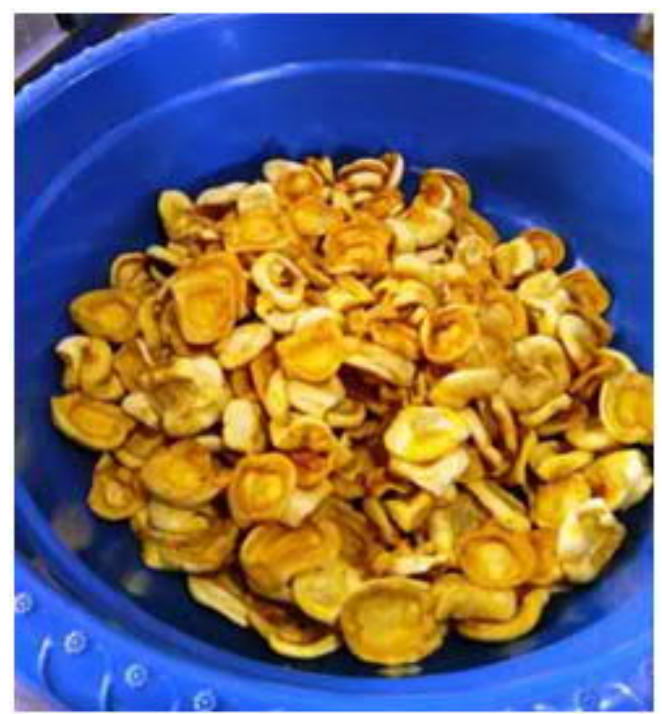

Gambar 3. Keripik Salak

3. Masyarakat mampu mengemas keripik salak ke dalam kemasan pangan yang baik (Gambar 4)

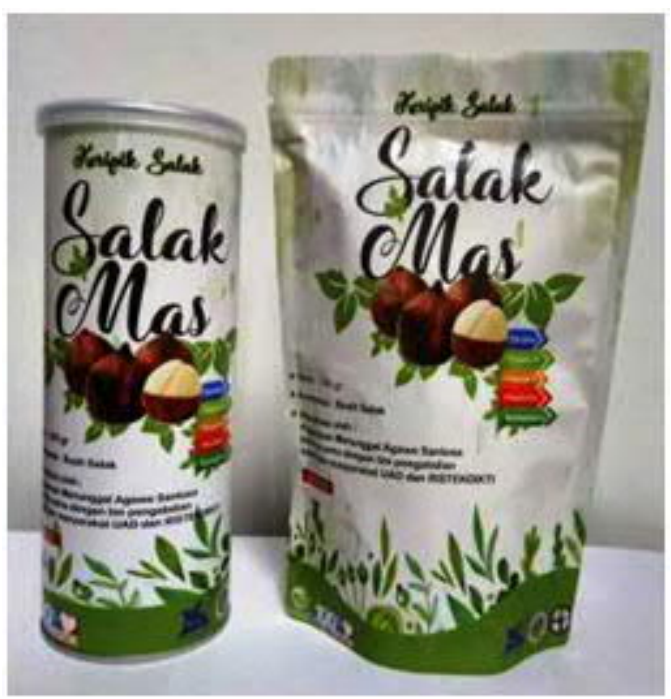

Gambar 4. Keripik Salak yang Telah Dikemas 
Tabel 1. Perbedaan produk olahan dari Paguyuban Purna TKI MAS sebelum dan setelah program pengabdian masyarakat

\begin{tabular}{llll}
\hline KRITERIA & SEBELUM & SETELAH & KETERANGAN \\
\hline Jumlah Produk & 4 produk & 6 produk & $\begin{array}{l}\text { Meningkat 2 produk yaitu keripik salak } \\
\text { dan keripik nangka }\end{array}$ \\
\hline Masa kadaluarsa produk & Produk lama: beberapa bulan & $\begin{array}{l}\text { Produk baru: lebih daril } \\
\text { tahun }\end{array}$ & Masa kadaluarsa meningkat \\
\hline Bahan kemasan & Produk lama: kemasan plastik & $\begin{array}{l}\text { Produk baru: aluminium } \\
\text { foil }\end{array}$ & $\begin{array}{l}\text { Dengan aluminium foil, produk lebih } \\
\text { higienis dan lebih tahan lama }\end{array}$ \\
\hline Bentuk kemasan & Produk lama: konvensional & Produk baru: lebih & $\begin{array}{l}\text { Dengan penambahan desain grafis, } \\
\text { memenuhi kaidah etiket kemasan, dan } \\
\text { penambahan varian bentuk kemasan }\end{array}$ \\
& & menarik & (standing pouch dan tabung) \\
\hline
\end{tabular}

Perubahan jumlah produk salak dinyatakan dengan Gambar 5:

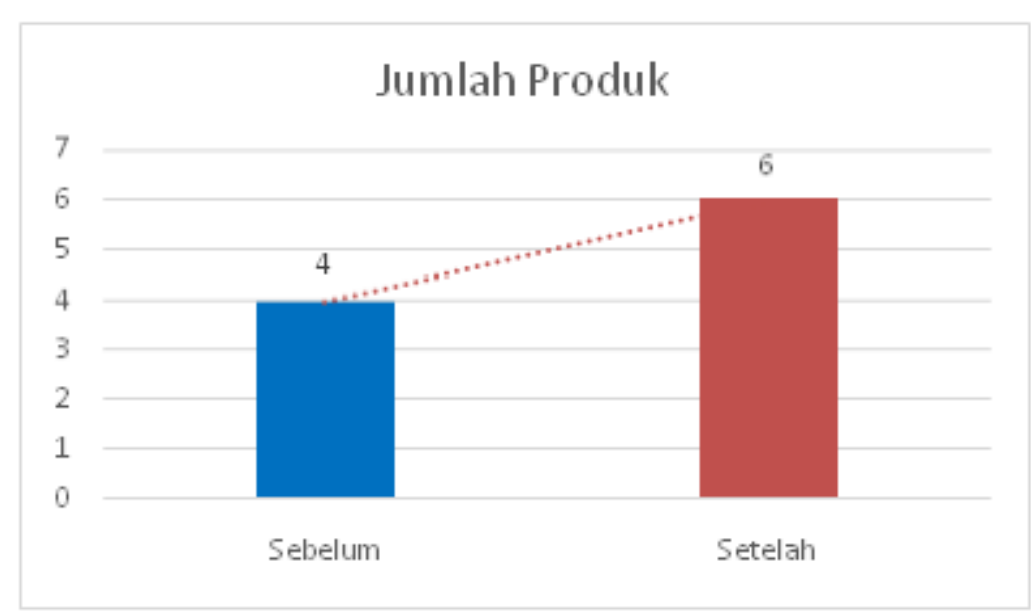

Gambar 5. Perbedaan jumlah produk salak sebelum dan sesudah program pengabdian masyarakat

Sedangkan perkembangan omzet mitra adalah sebagai berikut:

Tabel 2. Peningkatan omzet mitra rata-rata perbulan

\begin{tabular}{llll}
\hline OMZET & SEBELUM & SETELAH & KETERANGAN \\
\hline Omzet rata-rata per bulan & Rp 4.500.000,- & Rp 5.500.000,- & Meningkat Rp 1.000.000,- \\
\hline
\end{tabular}

Tabel 2 memperlihatkan bahwa omzet mitra setelah program pengabdian meningkat $22,22 \%$. Dampak program pengabdian masyarakat terhadap perkembangan omzet mitra juga dapat dilihat pada Gambar 6 . 


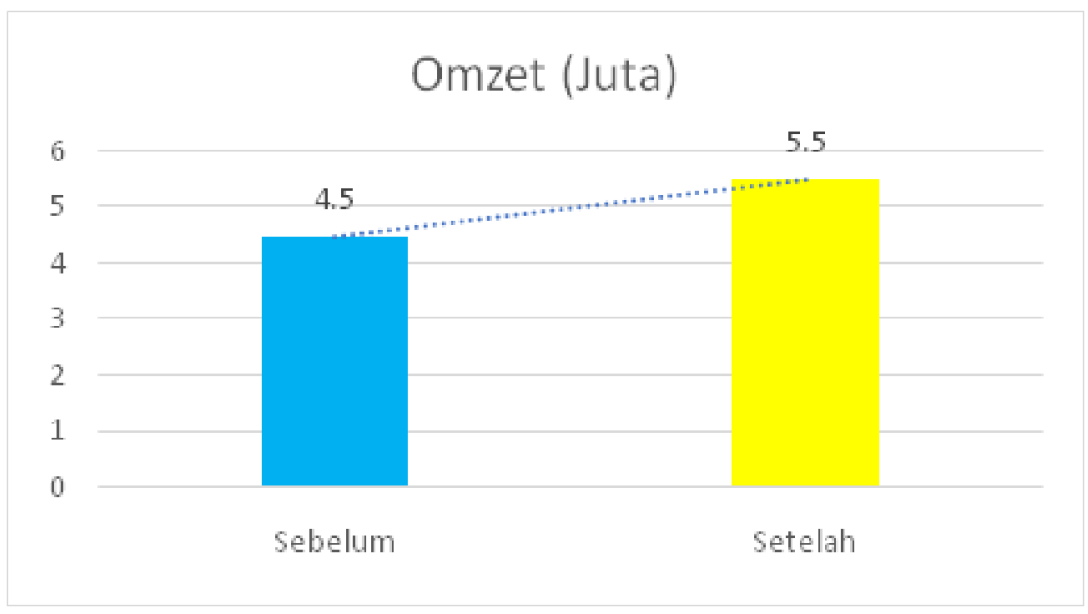

Gambar 6. Perbandingan omzet mitra sebelum dan sesudah pengabdian

Tiga program kerja yang dijalankan tim pengabdian masyarakat berupa pengolahan salak menjadi keripik salak, perbaikan manajemen produksi dan perbaikan manajemen pemasaran. Setelah ketiga program dijalankan, dilakukan program keempat berupa evaluasi program. Evaluasi dilakukan dengan membandingkan pengetahuan dari anggota mitra sebelum dan setelah program. Hasil yang diperoleh dapat dilihat pada Tabel 3 berikut:

Tabel 3. Hasil evaluasi peningkatan pemahaman dan kemampuan mitra sebelum dan setelah program.

\begin{tabular}{lll}
\hline NO & KRITERIA & PENINGKATAN (\%) \\
\hline 1 & Kemampuan usaha pengolahan buah salak & $8,11 \%$ \\
2 & Kemampuan mengolah buah salak menjadi keripik salak & $64,86 \%$ \\
3 & Kemampuan memperbanyak jumlah produk olahan buah salak & $62,16 \%$ \\
4 & Kemampuan menjelaskan langkah-langkah pengolahan keripik salak menggunakan alat vacuum frying & $91,89 \%$ \\
5 & Kemampuan mengemas produk keripik salak & $32,43 \%$ \\
6 & Pemahaman persyaratan produksi olahan makanan yang baik (manajemen, sanitasi fasilitas dan lingkungan & $83,78 \%$ \\
& kerja, higienitas karyawan) & \\
7 & Kemampuan memasarkan produk keripik salak & $40,54 \%$ \\
8 & Kemampuan menggunakan media sosial (Facebook, Instagram, website) untuk memasarkan produk olahan & $67,57 \%$ \\
& salak & \\
9 & Saya mampu memasarkan keripik salak menggunakan media transaksi online (marketplace) & $78,38 \%$ \\
\hline
\end{tabular}

Hasil evaluasi memperlihatkan terjadi peningkatan pengetahuan dan kemampuan dari anggota mitra dengan peningkatan rata-rata sebesar 58,40\%. Peningkatan kemampuan yang sangat signifikan adalah kemampuan pengoperasian mesin vacuum frying. Kemampuan manajemen produksi dan pemasaran meningkat di atas 60\%. Dengan demikian program pengabdian masyarakat berhasil dijalankan sesuai tujuan. 


\section{SIMPULAN}

Kegiatan pengabdian kepada masyarakat ini mampu melakukan transfer teknologi kepada masyarakat berupa penggunaan alat vacuum frying. Hal ini ditunjukkan dengan hasil perhitungan kuantitatif sebesar $58,40 \%$ peningkatan pengetahuan dan keahlian masyarakat. Selain itu, sebanyak $60 \%$ masyarakat mengalami peningkatan manajerial produksi dan pemasaran.

\section{UCAPAN TERIMA KASIH}

Tim Pengabdian Kemitraan Masyarakat (PKM) UAD mengucapkan terima kasih kepada Kementerian RISTEKDIKTI yang telah memberikan hibah pendanaan sehingga terwujudnya program ini. Kami mengucapkan terima kasih pula kepada Paguyuban Manunggal Agawe Santosa (MAS) yang telah menerima dan bekerja sama secara aktif hingga program ini dapat terselenggara dengan sukses. Kami ucapkan terima kasih kepada Universitas Ahmad Dahlan yang telah menyokong pelaksanaan teknis kegiatan. Kami ucapkan terima kasih pula kepada para mahasiswa yang telah membantu selama proses kegiatan dari awal hingga akhir.

\section{DAFTAR PUSTAKA}

Bremeer, Rachel., Syane Palijama, dan Febry R. Palijama. 2018. Pengaruh Pengaturan Suhu Penggorengan Vacum Terhadap Sifat-Sifat Kimia Keripik Salak (Salaca edulis Reinw). AGRITEKNO, Jurnal Teknologi Pertanian. Vol. 7(2):56-59. ISSN 2620-9721.

Dueik V, Robert P, and Bouchon P. 2010. Vacuum frying Reduce Oil Uptake and Improves The Quality Parameters of Carrot Crisps. Food Chemistry 119: 1143-1149.

Garayo J. and R. Moreira 2002. Vacuum frying of Potato Chips. Journal of Food Engineering 55: 181-191

Iswari, N.M.C. 2013. Optimasi suhu dan waktu penggorengan hampa (vacuum frying) dalam produksi keripik ubi jalar Mentawai. [Skripsi] Departemen Teknik Mesin dan Biosistem, Fakultas Teknologi Pertanian, Institut Pertanian Bogor. Bogor.

Mariscal M, and Bouchon P. 2007. Comparison between Atmospheric and Vacuum frying of Apple Slices. Journal Food Chemistry 107: 1561-1569 Nugraha, S., Sugiyanto, N.F. Sulvana, R. Tito, dan K.
Titis. 2012. Elastisitas dan Permintaan Hasil Pertanian. Makalah Tataniaga Pertanian, Universitas Sebelas Maret. Surakata.

Tumbel, Nicolas dan Supardi Manurung. 2017. Pengaruh Suhu Dan Waktu Penggorengan Terhadap Mutu Keripik Nanas Menggunakan Penggoreng Vakum. Jurnal Penelitian Teknologi Industri Vol. 9 No. 1 Juni 2017 : 9-22. ISSN No.2085-580X

Wijayanti R. 2011. Kajian Rekayasa Proses Penggorengan Hampa dan Kalayakan Usaha Produksi Keripik Pisang [tesis]. Bogor: Sekolah Pascasarjana, Institut Pertanian Bogor.

Wijayanti, R., I.W. Budiastra, dan R. Hasbullah. 2011. Kajian rekayasa proses penggorengan hampa dan kelayakan usaha produksi keripik pisang. Jurnal Keteknikan Pertanian 25: 133 140 